\title{
Proliferação, Apoptose e Histomorfometria da Glândula Mamária de Ratas Tratadas Com Tiroxina na Lactação e ao Desmame e Desenvolvimento dos Filhotes
}

\section{artigo original}

EVELINE DIAS LEITE

EDMILSON SANTOS DE FREITAS

CÍNTIa de Almeida SOUza

Natalia de Melo Ocarino

Geovanni Dantas Cassall

ENIO FERREIRA

MARDELeNE GeISA GoMes

ROgÉRIA SERAKIDES

Laboratório de Patologia

Comparada, Departamento de

Patologia Geral, Instituto de

Ciências Biológicas - UFMG,

Belo Horizonte, MG.

Recebido em 22/06/06

Revisado em 18/01/07

Aceito em 14/03/07

\section{RESUMO}

O objetivo deste estudo foi avaliar a histomorfometria e a taxa de proliferação e apoptose da glândula mamária de ratas tratadas com tiroxina pela imunoexpressão de CDC-47 e caspase-3, respectivamente. Também foi avaliado o desenvolvimento dos filhotes de ratas tratadas com tiroxina. Foram utilizadas 36 ratas distribuídas em dois grupos, tratado com tiroxina e controle. Após 60 dias de tratamento com tiroxina, as ratas foram acasaladas. Seis animais/grupo foram sacrificados no $2^{\circ}$ e $21^{\circ}$ dias de lactação e no $5^{\circ}$ dia após o desmame. Houve diferença significativa entre grupos apenas no quinto dia após o desmame. $O$ tratamento com tiroxina aumentou a taxa de apoptose caracterizada pela maior expressão de caspase-3 nas células do epitélio mamário. As mães tratadas com tiroxina apresentaram comportamento alterado, mas não houve diferença significativa no que se refere aos cuidados com o filhote quanto a higienização e aquecimento. Levando-se em consideração o sexo e o tamanho da ninhada, os filhotes das ratas tratadas com tiroxina e controle não apresentaram diferença significativa de peso ao desmame. Conclui-se que a administração de baixas doses de tiroxina aumenta a taxa de apoptose, caracterizada pelo aumento da expressão de caspase-3 no epitélio mamário cinco dias após o desmame, mas não altera a taxa de proliferação celular e o comportamento materno. (Arq Bras Endocrinol Metab 2007;51/6:1000-1006)

Descritores: Glândula mamária; Tiroxina; Lactação; CDC-47; Caspase-3; Rata

\section{ABSTRACT}

Proliferation, Apoptosis and Mammary Gland Histomorphometry of Thyroxine-Treated Rats on Lactation and After Weaning and Development of Offspring.

The purpose of this study was to evaluate mammary gland histomorphometry and proliferation rate and apoptosis of thyroxine-treated rats by CDC- 47 and caspase-3 immunoexpression. The development of thyroxine-treated rats offspring was also evaluated. Thirty-six female rats were used, distributed in two groups, treated and non-treated with thyroxine. After 60 days of treatment, with thyroxine, rats were mated. Six animals/group were sacrificed on the $2^{\text {nd }}$ and $21^{\text {st }}$ days of lactation and on the $5^{\text {th }}$ day after weaning. A significant difference was observed between groups only on the $5^{\text {th }}$ day after weaning. Thyroxine treatment increased apoptosis rate, which was characterized by a higher caspase-3 expression in mammary epithelial cells. Thyroxine-treated mothers presented changed behavior, but there was no significant difference regarding taking care of offspring, as for cleaning offspring and keeping them warm. Taking into account sex and size of offspring, those from control and thyroxine-treated mothers presented no significant difference of weight and weaning. In conclusion, administering low doses of thyroxine increases apoptosis rate, which is characterized by the increased caspase- 3 immunoexpression in mammary epithelial cells 5 days after weaning. But does not affect proliferation rate and development of thyroxine-treated rats offspring. (Arq Bras Endocrinol Metab 2007;51/6:1000-1006)

Keywords: Mammary gland; Thyroxine; Lactation; CDC-47; Caspase-3; Rat 
A PROLIFERAÇÃo E A DIFERENCIAÇÃo do epitélio mamário, durante a puberdade, gestação e lactação, estão sob o controle de vários hormônios, sendo principais o estrógeno, a progesterona, a prolactina (PRL), o hormônio do crescimento $(\mathrm{GH})$, a insulina, os hormônios tireoidianos, os glicocorticóides, a ocitocina e uma variedade de fatores de crescimento semelhantes à insulina $(1,2)$.

Nas fềmeas púberes não gestantes, a população de células epiteliais é minoria na glândula mamária, sendo esta constituída predominantemente por tecido adiposo. A gestação induz o desenvolvimento epitelial associado à redução do tecido adiposo. Durante a lactação, a maior parte da glândula mamária é representada pelos ácinos secretórios, havendo hipertrofia das células epiteliais e distensão dos alvéolos pelo acúmulo de secreção láctea. Após o desmame, a glândula mamária involui, o epitélio secretório sofre apoptose e o tecido adiposo reassume como o principal constituinte da glândula (2).

Os hormônios tireoidianos, além de participarem do desenvolvimento da glândula mamária, aumentam a síntese e a secreção de algumas proteínas do leite, como a alfa-lactoalbumina (3). Além disso, para que os principais hormônios galactopoéticos, tais como o GH e a PRL, atuem na glândula, é essencial a participação dos hormônios tireoidianos. O GH, a PRL e a T4 aumentam a atividade da 5'desiodase na glândula mamária, enzima que converte a tiroxina (T4) em triiodotironina (T3), forma metabolicamente ativa do hormônio tireoidiano (4-6).

Os efeitos da administração de tiroxina são amplamente conhecidos em vários sistemas (7), mas a literatura ainda carece de informação quanto ao efeito da tiroxina na glândula mamária durante e após a lactação e no comportamento materno em associação com o desenvolvimento dos filhotes. Além do mais, estudar o mecanismo de ação dos hormônios tireoidianos nos diversos estados funcionais da glândula mamária é relevante, visto a importância que se tem dado, atualmente, para a participação dos hormônios tireoidianos no desenvolvimento de determinados tumores, particularmente para o câncer de mama (8).

A tiroxina acelera o desenvolvimento da glândula mamária e a lactogênese $(9,10)$ e promove involução mamária precoce por aumentar a apoptose (2). No entanto, postula-se que apesar de a taxa de apoptose na glândula mamária de ratas tratadas com tiroxina ser mais elevada, a taxa de proliferação também seria. Assim, a fim de verificar se há realmente precocidade na involução da glândula mamária, o melhor seria o estudo concomitante não somente da taxa de apoptose como também da taxa de proliferação celular, um dos principais objetivos deste estudo.
O efeito da administração de tiroxina no comportamento materno tem sido divergente. Há estudos que demonstram que ratas tratadas com tiroxina apresentam comportamento materno inadequado (10), enquanto outros demonstram o contrário (2). Um fato que pode ter contribuído para tal divergência é a dose de tiroxina utilizada. Em alguns experimentos, a dose de tiroxina é tão elevada que há passagem de tiroxina, via leite, para os filhotes, em quantidade suficiente para provocar a morte dos mesmos (2). Além do mais, a heterogeneidade nos critérios adotados para caracterizar o comportamento materno também contribui para a diversidade de resultados.

O objetivo deste estudo foi avaliar o efeito da administração de baixas doses de tiroxina na histomorfometria e na taxa de proliferação e apoptose da glândula mamária pela imuno-expressão de CDC47 e caspase-3, respectivamente, e avaliar também o desenvolvimento dos filhotes de ratas tratadas com tiroxina durante todo o período de amamentação.

\section{MATERIAL E MÉTODOS}

Foram utilizadas 36 ratas Wistar adultas com 45 dias de idade. Os animais foram alojados em caixas plásticas (seis animais/caixa), recebendo ração comercial ( $1,4 \%$ de cálcio, $0,6 \%$ de fósforo e $22 \%$ de proteína) e água ad libitum. As ratas foram mantidas em regime de 12 horas de luz e 12 horas de escuro. Após sete dias de adaptação, os animais foram divididos em dois grupos experimentais, controle e tratado, cada um composto por 23 animais. Os animais do grupo tratado receberam tiroxina [L-thyroxine, Sigma, Saint Louis, USA (T2376)] na água de beber, na concentração de $1,6 \mu \mathrm{g} / \mathrm{ml}$, durante a indução, e de $0,8 \mu \mathrm{g} / \mathrm{ml}$, durante a gestação e a lactação. Os animais do grupo não tratado (controle) receberam apenas água, como placebo.

A partir do consumo médio de água ingerido por animal, por dia, estimou-se que a dose diária de tiroxina ingerida por animal foi de $60,43 \mu \mathrm{g} \pm 8,82$, durante a indução e de $39,72 \mu \mathrm{g} \pm 8,85$, durante a gestação e lactação.

Após dois meses do início do tratamento, as ratas de cada grupo eram colocadas com ratos machos adultos, em uma proporção de quatro fềmeas para cada macho, durante a noite por um período de 12 horas. Após o acasalamento, pela manhã, era realizada citologia vaginal. A cópula era confirmada pela presença de espermatozóides no esfregaço vaginal, e este dia era designado como dia 0 . As fêmeas que não apresentaram espermatozóides na citologia vaginal eram colocadas novamente com machos na noite seguinte, até que se encontrassem espermatozóides na citologia vaginal.

A partir dos 19 dias de gestação até o momento da eutanásia, cada fềmea gestante era isolada em caixas plásticas. Logo após o parto, foi realizada a sexagem e a quantificação dos filhotes vivos e mortos de cada mãe. O peso médio dos 
filhotes machos e fêmeas foi determinado no dia do nascimento e, posteriormente, a cada 48 horas. Diariamente, eram verificados quantos filhotes tinham aberto os olhos na ninhada. A partir destes dados, foi calculada a média ponderada da idade de abertura dos olhos dos filhotes de cada ninhada.

O comportamento materno também foi avaliado, diariamente, duas vezes ao dia (9:00 e 17:00), durante os 21 dias de amamentação, quanto à presença ou não de um ou mais filhotes não aquecidos e não higienizados na ninhada.

Seis fềmeas dos grupos, tratado e controle, foram sacrificadas no $2^{\circ}$ e $21^{\circ}$ dias de lactação e no $5^{\circ}$ dia após o desmame. Os filhotes foram sacrificados com sobredose de pentobarbital sódico $2,5 \%(30 \mathrm{mg} / \mathrm{Kg})$, por via intraperitonial. O sacrifício das fêmeas foi realizado por punção cardíaca precedida por anestesia com pentobarbital sódico, por via intra-peritoneal.

À necropsia, foram colhidos os pares de glândula mamária, abdominal caudal e inguinal. Imediatamente, esse tecido foi fixado em formalina a $10 \%$, neutra e tamponada, e processado pela técnica rotineira de inclusão em parafina (11). Cortes histológicos de $4 \mu \mathrm{m}$ da glândula mamária foram corados pela técnica da hematoxilina-eosina para avaliação histomorfométrica. Foi determinada, com objetiva de $40 \times$, a porcentagem de epitélio, de tecido adiposo, de estroma e de secreção. Na glândula mamária de ratas no quinto dia de desmame, a determinação da porcentagem dos componentes estruturais da glândula foi realizada em cortes histológicos corados pelo tricrômio de Masson. Essa coloração foi utilizada pela dificuldade, neste período, em se diferenciar o estroma do compartimento epitelial em secções coradas pela hematoxilina-eosina. A porcentagem de cada um dos componentes da glândula foi determinada em um total de 40 campos escolhidos aleatoriamente, que abrangiam toda a área da secção histológica. Para determinação dessas variáveis foi realizada a captura de imagens em câmera digital Spot Insigh Color adaptado a um microscópio Olympus BX-40, e utilizado o software de captura SPOT ${ }^{\circledR}$ versão 3.4.5. Utilizouse o software Corel DRAW ${ }^{\circledR}$ versão 7.468 para análise das imagens. Foram determinados 25 pontos eqüidistantes no campo da imagem histológica obtida, com contabilização de 1.000 pontos por lâmina examinada.

O número de campos utilizados para análise morfométrica descrita anteriormente foi determinado pela técnica de estudo da variação da instabilidade de valores médios em relação à amostra que os originou. Em um corte histológico da glândula mamária do grupo controle foi determinada a porcentagem de epitélio, de tecido adiposo, de estroma e de secreção em 100 campos. A seguir, os dados foram sorteados ao acaso em dez grupos. Foram determinados a média, o desviopadrão e o coeficiente de variação de cada variável em 10, 20, $30,40,50,60,70,80,90$ e 100 campos. Após verificar que o desvio-padrão e o coeficiente de variação se estabilizavam em torno de 40 campos, este número foi adotado para se determinar as porcentagens das estruturas do tecido mamário (12).

A atividade proliferativa e a detecção de apoptose na glândula mamária foram avaliadas pelo estudo imunoistoquímico com a utilização do marcador de proliferação ce- lular CDC47-Clone 47DCl41 (NeoMarkers) e o anticorpo anti-caspase-3 Clone RB-1197-P (NeoMarkers) (Dako, USA), respectivamente.

Para a análise imunoistoquímica, foram obtidos cortes histológicos de $4 \mu \mathrm{m}$ da glândula mamária. Foi utilizada a técnica de estreptavidina-biotina-peroxidase (Ultra vision large volume detection system anti-polyvalent, HRP - ready to use - Lab Vision), sendo empregada a técnica de recuperação antigênica através da utilização de solução Retrieval, durante 20 minutos. As lâminas foram incubadas em câmera úmida por 1 hora com o anticorpo primário (CDC47 - diluição de 1:200 ou Caspase 3 - 1:300) (Novacastra Laboratories, United Kingdom) e por 15 minutos nas etapas de bloqueio da peroxidase endógena, soro de bloqueio (Ultra Vision Block, Lab Vision), anticorpo secundário (Biotin Goat, Lab Vision) e estreptavidina peroxidase (Streptavidin Peroxidase, Lab Vision). O cromógeno utilizado foi o DAB (DAB Substrate System, Lab Vision), em incubação durante 10 minutos. As secções foram contra-coradas com hematoxilina de Harris.

Como controle positivo interno para o CDC-47, utilizou-se a própria pele que recobria a glândula mamária, e como controle positivo para a caspase- 3 foram utilizados cortes de baço de ratas previamente testados. O controle negativo foi obtido pela substituição do anticorpo primário por solução tampão.

O número médio de células com expressão de CDC-47 e de caspase- 3 foi determinado com objetiva de $60 \times$ em 10 campos aleatórios, que abrangiam toda a área da secção histológica. Para a quantificação também foi realizada a captura de imagens em câmera digital Spot Insight Color adaptado a um microscópio Olympus BX-40, e utilizado o software de captura SPOT ${ }^{\circledR}$ versão 3.4.5. Utilizou-se o software Corel DRAW ${ }^{\circledR}$ versão 7.468 para análise das imagens.

O delineamento utilizado foi inteiramente ao acaso com fatorial $2 \times 3$ (dois grupos $\times$ três períodos). Para cada variável, a média e o desvio-padrão foram determinados. Os dados foram submetidos à análise de variância ANOVA do programa estatístico Instat (Graph Pad Software, Versão 3.00, 32 Win 95/NT, criado em Dezembro de 1997) e as médias foram comparadas pelo teste SNK. O peso dos filhotes foi submetido à análise de covariância a fim de retirar o efeito do tamanho da ninhada no peso médio dos filhotes. O comportamento materno foi avaliado pelo teste de $\chi^{2}$, considerando-se a presença ou a ausência de ninho, presença ou ausência de filhotes sujos e presença ou ausência de filhotes hipotérmicos. A idade de abertura dos olhos dos filhotes foi analisada pelo teste t não pareado (12).

\section{RESULTADOS}

\section{Histomorfometria da glândula mamária}

No $2^{\circ}$ e $21^{\circ}$ dias de lactação, independentemente dos grupos, a glândula mamária apresentava alvéolos distendidos, repletos por secreção láctea e revestidos por epitélio pavimentoso (figuras 1 e 2). Os ductos tam- 
bém se apresentavam distendidos, às vezes repletos de secreção e revestidos por epitélio pseudoestratificado. Havia, ainda, moderada quantidade de tecido adiposo entremeado aos alvéolos. O estroma era moderado. A análise morfométrica comprovou a semelhança da glândula mamária entre os grupos, não havendo diferença significativa com relação à porcentagem dos componentes estruturais da glândula (tabelas 1 a 4).

No $5^{\circ}$ dia após o desmame, também não houve diferenças entre grupos no que se refere à porcentagem dos componentes estruturais da glândula (tabelas 1 a 4). Os alvéolos distribuíam-se desorganizadamente pela secção histológica, os lúmens alveolares apresentavam pequena quantidade de secreção láctea com células epiteliais descamadas com núcleos pequenos e condensados ou fragmentados, características de apoptose. As células do epitélio alveolar apresentavam-se cuboidais, de permeio a células mioepiteliais e moderada quantidade de estroma (figura 3). Havia, ainda, grande quantidade de tecido adiposo entremeado aos alvéolos e moderada infiltração multifocal de leucócios, principalmente, mastócitos, monócitos, linfócitos e eosinófilos.

\section{Proliferação celular e apoptose no tecido mamário}

$\mathrm{O}$ índice de proliferação celular, determinado pela expressão de CDC-47 nas células do epitélio mamário, não diferiu significativamente entre os grupos, em nenhum dos períodos estudados. Tanto no grupo tratado com tiroxina quanto no grupo controle, houve redução significativa da taxa de proliferação no final do período de lactação em comparação ao início da lactação (tabela 5).

Durante a lactação, não houve diferença significativa entre grupos no que concerne à taxa de apoptose no epitélio mamário. Mas, após o desmame, o número de células em apoptose na glândula mamária das ratas do grupo tratado com tiroxina, caracterizado pela maior expressão de caspase-3, foi quase o dobro do valor encontrado na glândula mamária das ratas do grupo controle, diferindo significativamente entre os grupos (figura 4, tabela 6). É importante salientar que esse aumento da taxa de apoptose após o desmame não foi acompanhado pelo aumento da taxa de proliferação celular, como postulado no início do experimento.

\section{Comportamento materno e desenvolvimento dos filhotes}

As mães do grupo controle mantinham os seus filhotes sempre juntos e no centro de um ninho bem formado. Quando um filhote se separava dos demais, a mãe do grupo controle prontamente se preocupava em colocálo junto aos demais. Ao contrario, a mãe tratada com tiroxina apresentava comportamento agressivo e era mais agitada, não se preocupando com a separação dos filhotes. Apesar disso, não houve diferença significativa entre grupos no que se refere ao cuidado das ratas com a prole em relação ao aquecimento e limpeza dos filhotes (dados não demonstrados).

O peso médio dos filhotes machos e fềmeas das mães tratadas com tiroxina não diferiu significativamente do peso médio dos filhotes das ratas controle, em nenhum período. Além disso, não houve diferença entre grupos quanto à idade de abertura dos olhos dos filhotes, que foi de 13,65 $\pm 0,87$ dias para o grupo controle e $13,94 \pm 0,81$ dias para o grupo tratado com tiroxina.

\section{DISCUSSÃo}

A redução da porcentagem de tecido adiposo na glândula mamária, independentemente do grupo, que ocorreu do segundo dia de lactação para o vigésimo primeiro dia de lactação, está relacionada com o desenvolvimento da glândula mamária, que nas ratas completa-se durante a lactação (13-15). Já o aumento na quantidade de tecido adiposo e a redução da secreção láctea que ocorreu do vigésimo primeiro dia de lactação para o quinto dia de desmame, está relacionado ao processo de involução da glândula e coincide com a diminuição no tamanho dos lóbulos alveolares (14).

A diminuição no número de células epiteliais que expressaram o CDC-47 aos 21 dias de lactação provavelmente ocorreu devido à menor concentração sérica de prolactina e GH. Estes hormônios estão relacionados com o comportamento materno e são fatores sobreviventes importantes para as células epiteliais da glândula mamária $(2)$.

A maior expressão de caspase-3 nas células do epitélio mamário de ratas tratadas com tiroxina sugere aumento da taxa de apoptose neste grupo e conseqüente involução precoce da glândula. A partir deste resultado, pode-se sugerir que o tratamento com tiroxina acelera o processo de involução da glândula mamária. Mas é importante ressaltar que a involução mamária não se caracteriza somente pela regressão dos elementos epiteliais por apoptose, mas também engloba o processo de remodelamento glandular, que está associada ao aumento da degradação proteolítica (16) e que não foi avaliado neste caso já que a análise somente foi realizada no quinto dia após o desmame.

Em estudo realizado anteriormente, foi encontrada maior expressão de SGP-2, gene relacionado à apoptose, na glândula mamária de ratas tratadas com elevadas doses de tiroxina, no décimo quarto e no vigésimo 

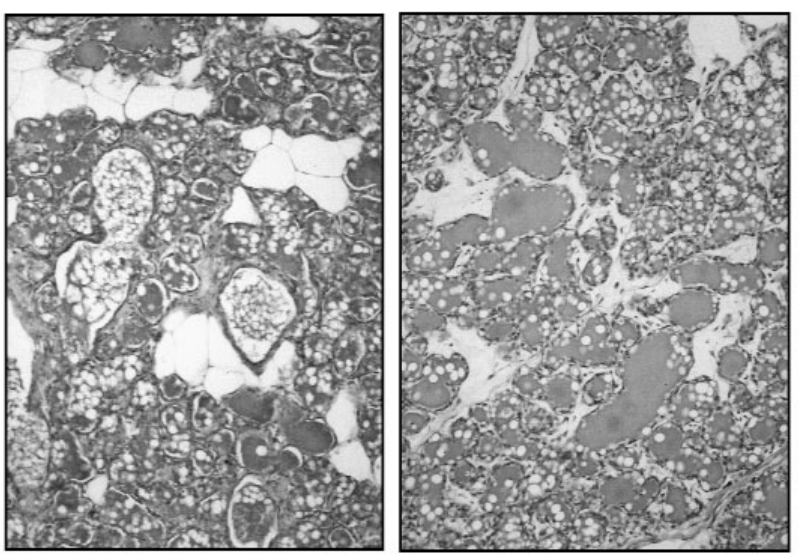

Figura 1. Glândula mamária de ratas, $2^{\circ}$ dia de lactação. $H E$, 257,71×. A) Grupo controle, alvéolos distendidos, revestidos por epitélio pavimentoso. B) Grupo tratado com tiroxina, alvéolos distendidos, revestidos por epitélio pavimentoso semelhante ao grupo controle.
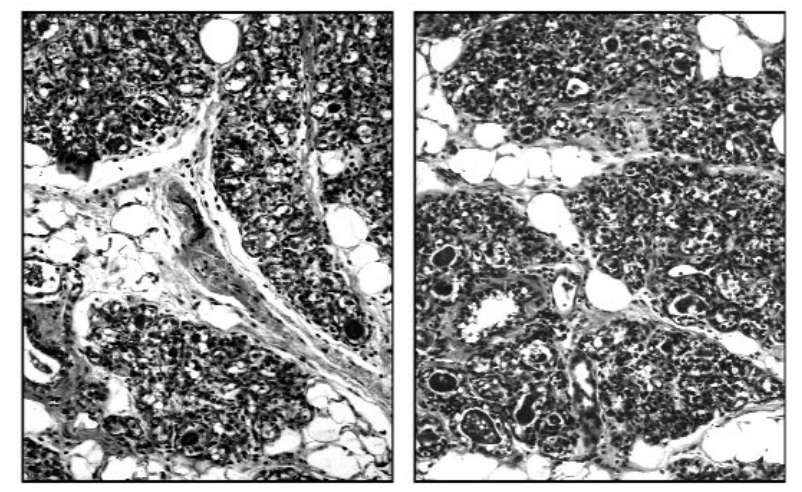

Figura 3. Glândula mamária de ratas, $5^{\circ}$ dia de desmame. Tricrômio de Masson, 259,14×. A) Grupo controle, alvéolos distribuídos desorganizadamente, lúmens alveolares com secreção láctea e pequena quantidade de tecido adiposo. B) Grupo tratado com tiroxina, alvéolos distribuídos desorganizadamente, lúmens alveolares com secreção láctea e moderada quantidade de tecido adiposo entremeado aos alvéolos.

Tabela 1. Porcentagem de secreção na glândula mamária de ratas dos grupos tratado com tiroxina e controle no $2^{\circ} \mathrm{e}$ $21^{\circ}$ dias de lactação e no $5^{\circ}$ dia após o desmame.

\begin{tabular}{lccc}
\hline Grupo & Período & \\
& $\begin{array}{c}\mathbf{2}^{\circ} \text { dia de } \\
\text { lactação }\end{array}$ & $\begin{array}{c}\mathbf{2 1}^{\circ} \text { dia de } \\
\text { lactação }\end{array}$ & $\begin{array}{c}5^{\circ} \text { dia após } \\
\text { o desmame }\end{array}$ \\
Controle & $31,7 \pm 11,91^{\mathrm{Aa}}$ & $41,4 \pm 8,62^{\mathrm{Aa}}$ & $4,17 \pm 4,87^{\mathrm{Ba}}$ \\
Tratado & $33,3 \pm 11,4 \mathrm{Aa}$ & $43,4 \pm 12,3^{\mathrm{Aa}}$ & $10,2 \pm 9,52^{\mathrm{Ba}}$ \\
\hline
\end{tabular}

* Médias com letras maiúsculas iguais na linha e letras

minúsculas iguais na coluna não diferem entre si $(p \geq 0,05)$.

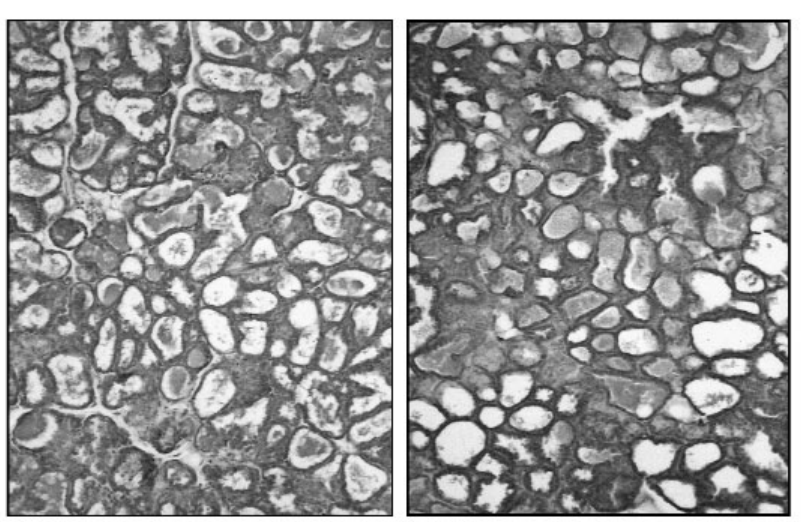

Figura 2. Glândula mamária de ratas, $21^{\circ}$ dia de lactação, experimento 2. HE, 249,43x. A) Grupo controle, alvéolos distendidos, revestidos por epitélio pavimentoso. B) Grupo tratado com tiroxina, alvéolos distendidos, revestidos por epitélio pavimentoso semelhante ao grupo controle.
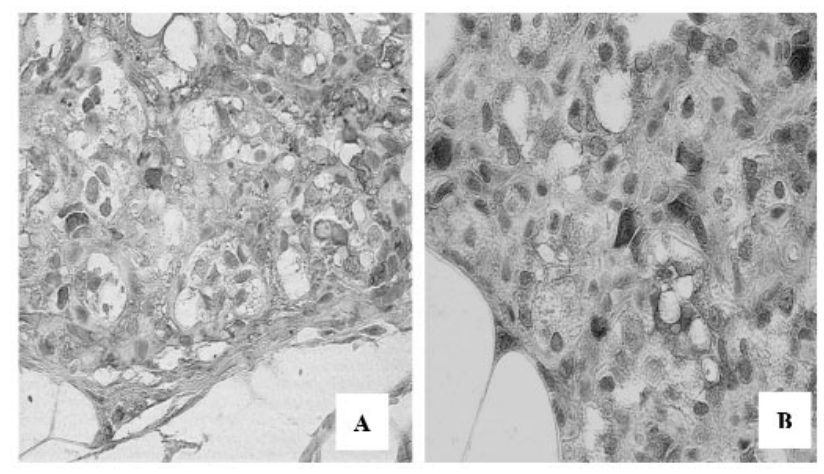

Figura 4. Glândula mamária de ratas, no $5^{\circ}$ dia de desmame. Imunomarcação para caspase-3, estreptoavidina-biotinaperoxidase, contra-coloração por hematoxilina de Harris, $583,57 \times$. A) Grupo controle, pequeno número de células marcadas (setas). B) Grupo tratado com tiroxina, grande número de células marcadas (setas).

Tabela 2. Porcentagem de epitélio na glândula mamária de ratas dos grupos tratado com tiroxina e controle no $2^{\circ}$ e $21^{\circ}$ dias de lactação e no $5^{\circ}$ dia após o desmame.

\begin{tabular}{|c|c|c|c|}
\hline Grupo & $\begin{array}{l}2^{\circ} \text { dia de } \\
\text { lactação }\end{array}$ & $\begin{array}{c}\text { Período } \\
21^{\circ} \text { dia de } \\
\text { lactação }\end{array}$ & $\begin{array}{l}5^{\circ} \text { dia após } \\
\text { o desmame }\end{array}$ \\
\hline Controle & $22,4 \pm 8,7 \mathrm{Ba}$ & $24,6 \pm 6,2^{\mathrm{Ba}}$ & $30,02 \pm 3,4 \mathrm{Aa}$ \\
\hline Tratado & $18,8 \pm 3,3^{C a}$ & $25,54 \pm 3,07 \mathrm{Ba}$ & $36,37 \pm 3,4 \mathrm{Aa}$ \\
\hline
\end{tabular}


Tabela 3. Porcentagem de tecido adiposo na glândula mamária de ratas dos grupos tratado com tiroxina e controle no $2^{\circ}$ e $21^{\circ}$ dias de lactação e no $5^{\circ}$ dia após o desmame.

\begin{tabular}{lccc}
\hline Grupo & $\begin{array}{c}\text { Período } \\
\text { lactação }\end{array}$ & $\begin{array}{c}\mathbf{2 1}^{\circ} \text { dia de } \\
\text { lactação }\end{array}$ & $\begin{array}{c}\mathbf{5}^{\circ} \text { dia após } \\
\text { o desmame }\end{array}$ \\
Controle & $30,5 \pm 13,0^{\mathrm{Aa} a}$ & $3,2 \pm 3,96^{\mathrm{Ca}}$ & $43,9 \pm 10,7^{\mathrm{Aa}}$ \\
Tratado & $28,7 \pm 9,2^{\mathrm{Ba}}$ & $1,14 \pm 0,77^{\mathrm{Ca}}$ & $41,7 \pm 8,2^{\mathrm{Aa}}$ \\
\hline
\end{tabular}

* Médias com letras maiúsculas iguais na linha e letras

minúsculas iguais na coluna não diferem entre si $(p \geq 0,05)$.

Tabela 5. Número médio de células epiteliais/campo com expressão de CDC-47 na glândula mamária de ratas do grupo controle e tratado com tiroxina no $2^{\circ}$ e $21^{\circ}$ dias de lactação e no $5^{\circ}$ dia após o desmame.

\begin{tabular}{lccc}
\hline \multirow{2}{*}{ Grupo } & \multicolumn{2}{c}{ Período } \\
& $\mathbf{2}^{\text {o dia de }}$ lactação & $\mathbf{2 1}^{\circ}$ dia de & $5^{\circ}$ dia após \\
lactação & o desmame \\
Controle & $238,3 \pm 78,9 \mathrm{Aa}$ & $140,4 \pm 52,1^{\mathrm{Ba}}$ & $205,4 \pm 68,8^{\mathrm{ABa}}$ \\
Tratado & $290,7 \pm 54,0^{\mathrm{Aa}}$ & $31,4 \pm 18,5^{\mathrm{Ba}}$ & $272,8 \pm 41,0 \mathrm{Aa}$ \\
\hline
\end{tabular}

* Médias com letras maiúsculas iguais na linha e letras minúsculas iguais na coluna não diferem entre si $(p \geq 0,05)$.

primeiro dias de lactação (2). No entanto, neste experimento, não houve diferença significativa entre os grupos com relação à expressão de caspase 3 nas células do epitélio mamário durante toda a lactação. Provavelmente isso se deveu à diferença na dose de tiroxina utilizada, 10 vezes menor em comparação à do experimento anterior (10). Além disso, a taxa de proliferação celular, determinada pela expressão de CDC-47, até então não mensurada em outros experimentos, não diferiu entre grupos no quinto dia após o desmame, afastando a suspeita de que o aumento da taxa de apoptose pudesse ter ocorrido concomitantemente ao aumento da taxa de proliferação.

Para se avaliar criteriosamente o comportamento materno, o peso dos filhotes e o tamanho da ninhada foram considerados, já que esta avaliação não havia sido realizada nos experimentos anteriores $(2,9,10)$. Em determinados dias da pesagem, o peso médio dos filhotes machos foi significativamente maior do que o das fêmeas. Essa diferença comprova a importância de se considerar o sexo do filhote na avaliação do peso. Como neste experimento a dose de tiroxina utilizada foi bem menor que a dose utilizada no experimento de Rosato (9), o risco da indução de hipertireoidismo nos filhotes foi menor, o que poderia influenciar negativamente nossos resultados, à semelhança do ocorrido em outros experimentos, nos quais toda a prole morreu antes do desmame $(2,9)$. As tireóides dos filhotes das ratas tratadas com tiroxina e controle apresentaram morfologia
Tabela 4. Porcentagem de estroma na glândula mamária de ratas do grupo controle e tratado com tiroxina no $2^{\circ}$ e $21^{\circ}$ dias de lactação e no $5^{\circ}$ dia após o desmame.

\begin{tabular}{|c|c|c|c|}
\hline \multicolumn{4}{|c|}{ Período } \\
\hline Grupo & $\begin{array}{l}2^{\circ} \text { dia de } \\
\text { lactação }\end{array}$ & $\begin{array}{l}21^{\circ} \text { dia de } \\
\text { lactação }\end{array}$ & $\begin{array}{l}5^{\circ} \text { dia após } \\
\text { o desmame }\end{array}$ \\
\hline Controle & $13,9 \pm 5,9 \mathrm{Ba}$ & $28,6 \pm 11,8 \mathrm{Aa}$ & $15,9 \pm 2,6^{\mathrm{Ba}}$ \\
\hline Tratado & $20,8 \pm 7,14^{\mathrm{Ba}}$ & $31,7 \pm 6,6 \mathrm{Aa}$ & $17,9 \pm 4,6 \mathrm{Ba}$ \\
\hline
\end{tabular}

* Médias com letras maiúsculas iguais na linha e letras minúsculas iguais na coluna não diferem entre si $(p \geq 0,05)$.

Tabela 6. Número médio de células epiteliais/campo com expressão de caspase 3 na glândula mamária de ratas do grupo controle e do grupo tratado com tiroxina no $2^{\mathrm{o}}$ e $21^{\circ}$ dias de lactação e no $5^{\circ}$ dia após o desmame.

\begin{tabular}{|c|c|c|c|}
\hline \multicolumn{4}{|c|}{ Período } \\
\hline Grupo & $\begin{array}{l}2^{o} \text { dia de } \\
\text { lactação }\end{array}$ & $\begin{array}{c}21^{\circ} \text { dia de } \\
\text { lactação }\end{array}$ & $\begin{array}{l}5^{\circ} \text { dia após } \\
\text { o desmame }\end{array}$ \\
\hline Controle & $12,7 \pm 2,8 \mathrm{Aa}$ & $9,4 \pm 2,7 \mathrm{Ba}$ & $12,6 \pm 3,0^{A b}$ \\
\hline Tratado & $16,2 \pm 3,2^{\mathrm{Ba}}$ & $10,3 \pm 1,4 \mathrm{Ca}$ & $23,9 \pm 7,7 \mathrm{Aa}$ \\
\hline
\end{tabular}

*Médias com letras maiúsculas iguais na linha e letras minúsculas iguais na coluna não diferem entre $s i(p \geq 0,05)$.

semelhante neste estudo (dados não demonstrados), o que indica não ter ocorrido passagem de tiroxina para o filhote, via leite, a ponto de influenciar o nível plasmático de TSH do feto. Como não houve diferença no peso médio dos filhotes e na idade de abertura dos olhos entre os filhotes de ratas tratadas com tiroxina e controle, podese concluir que as ratas tratadas com tiroxina apresentaram comportamento materno adequado.

\section{CONCLUSÕES}

O tratamento de ratas com baixas doses de tiroxina não altera a morfologia, a porcentagem dos componentes da glândula mamária e a taxa de proliferação celular de ratas durante a lactação e ao desmame; não altera a expressão de caspase-3 durante a lactação, mas aumenta a sua expressão ao desmame, sugerindo involução precoce da glândula mamária; não altera o comportamento materno com a prole em relação ao aquecimento, limpeza e desenvolvimento dos filhotes.

\section{REFERÊNCIAS}

1. Thordarson G, Fielder P, Lee C, Kit Hom Y, Robleto D, Ogren $\mathrm{L}$, et al. Mammary gland differentiation in hypophysectomized, pregnant mice treated with corticosterone and thyroxine. Biol Reprod 1992;47:676-82. 
2. Varas SM, Muñoz EM, Hapon MB, Aguiela Merlo Cl, Giménez MS, Jahn GA. Hyperthyroidism and production of precocious involution in the mammary gland of lactating rats. Reproduction 2002;124:691-702.

3. Ramos CF, Teixeira CV, Passos MC, Pazos-Moura CC, Lisboa PC, Curty FH, et al. Low-protein diet changes thyroid function in lactating rats. Proc Soc Exp Biol Med 2000;224:256-63.

4. Griffith DR, Turner CW. Thyroxine and mammary gland growth in rat. Proc Soc Exp Biol Med 1961;106:873-4.

5. Kumaresan P, Turner CW. Effect of growth hormone and thyroxine on mammary gland growth in the rat. $\mathbf{J}$ Dairy Sci 1965:48:492-5.

6. Capuco AV, Kahl S, Jack LJW, Bishop JO, Wallace EH. Prolactin and growth hormone stimulation of lactation in mice requires thyroid hormones. Proc Soc Exp Biol Med 1999;221:345-51.

7. Trivalle C, Doucet J, Chassagne P, Landrin I, Kadri N, Menard $J F$, et al. Differences in the signs and symptoms of hyperthyroidism in older and younger patients. J Am Geratr Soc 1996;44:50-3.

8. Ferreira E, Silva AE, Serakides R, Gomes MG, Cassall GD. Ehrlich tumor as model to study artificial hyperthyroidism influence on breast cancer. Pathol Res Pract 2007;203:3944.

9. Rosato RR, Jiménez MS, Jahn GA. Effects of chronic thyroid hormone administration on pregnancy, lactogenesis and lactation in the rat. Acta Endocrinol 1992;127:547-54.

10. Rosato R, Lindenbergh-Kortleve D, Neck J, Drop S, Jahn G. Effect of chronic thyroxine treatment on IGF-I, IGF-II and IGFbinding protein expression in mammary gland and liver during pregnancy and early lactation in rats. Eur $\mathbf{J}$ Endocrinol 2002;146:729-39.
11. Prophet EB, Mills B, Arrington JB, et al. Afip Laboratory Methods in Histotechnology. Washington: Am. Registry of Pathology, 1992. p. 278.

12. Sampaio IBM. Estatística aplicada à experimentação animal. $2^{\mathrm{a}}$ ed. Belo Horizonte: FEPMVZ, 2002. p. 265.

13. Deloius C, Richard P. Lactation. In: Thibault C, Levasseur MC, Hunter RHF. Reproduction in Mammals and Man. Paris: Ellipses, 1993. pp. 503-29.

14. Masso-Welch PA, Darcy KM, Stangle-Castor NC, Margot M. A developmental atlas of rat mammary gland histology. $\mathbf{J}$ Mammary Gland Biol Neoplasia 2000;5(2):165-85.

15. Knight $\mathrm{CH}$, Peaker $\mathrm{M}$. Development of the mammary gland. $\mathbf{J}$ Reprod Fert 1982;65:521-36.

16. Accorsi PA, Pacioni B, Pezzi C, Forni M, Flint DJ, Seren E. Role of prolactin, growth hormone and insulin-like growth factor 1 in mammary gland involution in the dairy cow. J Dairy Sci 2002;85:507-13.

\section{Endereço para correspondência:}

Rogéria Serakides

Setor de Patologia, Depto. de Clínica e Cirurgia Veterinárias Universidade Federal de Minas Gerais

Av. Pres. Antônio Carlos 6627

Caixa Postal 567

31270-901 Belo Horizonte, MG

Fax: (31) 3499-2230

E-mail: serakide@dedalus.lcc.ufmg.br 